\title{
Adherence to Iron and Folic Acid Supplements and Associated Factors Among Pregnant Mothers Attending ANC at Gulele Sub-City Government Health Centers in Addis Ababa, Ethiopia
}

\author{
Eleni Tegodan' \\ Gurmesa Tura $\mathbb{( D}^{2}$ \\ Ayantu Kebede $\mathbb{1}^{3}$ \\ 'Addis Ababa, Gulele Sub City, Hidase \\ Health Center, Addis Ababa, Ethiopia; \\ ${ }^{2}$ Jimma University, Institute of Health, \\ Department of Population and Family \\ Health, Jimma, Ethiopia; Jimma \\ University, Institute of Health, \\ Department of Epidemiology, Jimma, \\ Ethiopia
}

\begin{abstract}
Background: Even though antenatal care (ANC) visits seems to be the key strategy to increase adherence to iron and folic acid supplements during pregnancy, the problem still remains unresolved. Therefore, this study planned to assess adherence to iron and folic acid supplements and associated factors among pregnant mothers attending ANC at Gulele subcity Government Health Centers in Addis Ababa, Ethiopia, 2019.

Methods: An institution-based cross-sectional study design was conducted on 403 pregnant women attending ANC at governmental health centers in Gulele sub city of Addis Ababa from May to June, 2019. The study participants were selected by systematic random sampling techniques, and an interviewer administered questionnaire was used to collect data. Descriptive statistics and logistic regression models were used to analyze the data. The results were considered statistically significant at p-value $<0.05$.
\end{abstract}

Results: The proportion of mother's adherent to iron and folic acid supplements was $62.3 \%$ with a 95\% CI of 57.5-67.0. Women who had no formal education (AOR=2.37; 95\% $\mathrm{CI}=1.25-4.51$ ), poor knowledge about anemia ( $\mathrm{AOR}=1.97$; 95\% $\mathrm{CI}=1.24-3.13)$, developing any other health problem during current pregnancy $(\mathrm{AOR}=2.59 ; 95 \% \mathrm{CI}=1.55-4.32)$, attending health information about iron/folic acid supplement $(\mathrm{AOR}=2.06 ; 95 \% \mathrm{CI}=1.08-3.921$ and forgetful ( $\mathrm{AOR}=2.23 ; 95 \% \mathrm{CI}=1.40-3.56)$ mothers were more likely to be non-adherent to the supplement compared with their counterparts.

Conclusion and Recommendation: The status of maternal adherence was medium compared with other studies, and maternal educational status, knowledge about anemia, exposure to information, experiencing of health problems, and forgetfulness were associated with adherence behavior. This indicates that improving dissemination of information about the supplements and designing a reminder mechanism was needed to improve the adherence status of mothers to the supplement.

Keywords: adherence, iron and folic acid supplement, pregnant mother, factors, antenatal care, Ethiopia

\section{Introduction}

Iron deficiency anemia is a problem of both developed and developing countries with human health, social and economic development consequences. Globally, it is estimated that $41.8 \%$ of pregnant women are anemic. ${ }^{1,2}$ In low and middle income countries overall $42.7 \%$ of women experienced anemia during pregnancy, which is
Correspondence: Ayantu Kebede Tel +251910170632

Email ayukebede2013@gmail.com 
associated with higher risk of low birth weight, preterm birth, perinatal mortality, and neonatal mortality. ${ }^{3}$

To combat the risk of anemia and neural tube defect, folic acid supplementation in combination with iron is one of the few effective public health interventions. ${ }^{4}$ Iron and Folate are important micronutrients required for normal functioning, growth, development, and immunity. ${ }^{5}$ A study conducted in 19 African countries found that receiving of at least $90 \mathrm{iron/folic} \mathrm{acid} \mathrm{(IFA)} \mathrm{supplements}$ through Antenatal Care (ANC) among pregnant women reduces the risk of neonatal mortality by $34 \% .{ }^{6,7}$

Despite WHO recommendations, the use of iron/folic acid supplementation is still low in many countries, especially in low resource countries. ${ }^{8-10}$ According to a 2016 Ethiopian Demographic and Health Survey (EDHS) there is great variation among urban and rural residents $(61 \%$ vs $39 \%$ ) on taking iron supplements. ${ }^{11}$

Even though many developing countries, including Ethiopia, are now implementing IFA supplementation through ANC programs, only a few countries have reported significant improvement in IFA supplementation and anemia control and prevention. ${ }^{12}$ Iron/folic acid supplementation is affected by many factors and maternal poor adherence to the regimen is the main reason for the ineffectiveness of the strategy to decrease maternal and child complications due to iron/folic deficiency. ${ }^{13,14}$.

Adherence to iron/folic acid supplement refers to the number of times pregnant women took the supplements in a week. According to different studies conducted in Ethiopia, taking the supplement at least for 4 days in a week is considered as compliant/adherent. Considering mothers should get IFA supplements for more than 90 days, Ethiopia has interventions and programs during pregnancy including Provision of IFA supplement to all pregnant women free of charge to prevent anemia and its complications. But still there is inconsistency in the IFA intake level due to different factors. ${ }^{15-17}$ Overall, different studies indicated that socioeconomic, obstetric, and medical status, different individual factors, supplement, and health service related factors affect adherence to the supplement. ${ }^{18-21 .}$

According to different studies conducted in different parts of Ethiopia, iron/folic acid supplementation adherence is a major problem and still remains unresolved. ${ }^{22}$ Thus, since there is no previous study that has been conducted in the study area with a similar purpose, this study planned to investigate adherence to iron/folic acid supplements and associated factors among ANC attending mothers in Gulele sub city governmental health centers in Addis Ababa, Ethiopia, in 2019.

\section{Methods and Materials Study Design and Setting}

An institution-based cross-sectional study design was conducted in governmental health centers found in Gulele Sub city, Addis Ababa, Ethiopia. Gulele sub city is one of the sub cities found in Addis Ababa, the capital city of Ethiopia to the Northern part of the city covering an area of $30.18 \mathrm{~km}^{2}$ with a total population of 351,694 , from which 168,813 were males and 182,881 were females. A total of 10 health centers are in the sub city, in which 656 pregnant mothers are expected to follow ANC per month. The study was conducted from May to June, 2019.

\section{Study Populations and Sampling Procedures}

The study populations were all pregnant women who visited the health centers found in the sub city at least for the second ANC visit and were supplemented with IFA tablets for at least 1 month. The sample size was determined using a single population proportion formula by assuming a $60.9 \%$ proportion of adherence to IFA supplements from a previous study, ${ }^{23} 95 \%$ confidence level, and 5\% margin of error. Then, the calculated sample size equals 366. After adding a non-response rate of $10 \%$, the final sample size becomes 403 . Generally, 10 health centers were found in Gulele sub city and all health centers were included inthe study. Based on the expected number of pregnant mothers attending ANC at each health center, the sample size was proportionally allocated. Finally, after checking the eligibility of the mother, individual study participants were selected using systematic random sampling techniques (Figure 1).

\section{Data Collection Techniques and Quality Control}

Data was collected using an interviewer administered questionnaire by face-to-face interview. The questionnaire was first prepared in English and translated to Amharic for data collection. The questionnaire consists of five parts including demographics, Pregnancy and Obstetricsrelated, Supplement-related, knowledge about Anemia, and Health system-related. Data was collected by five trained diploma nurses. 


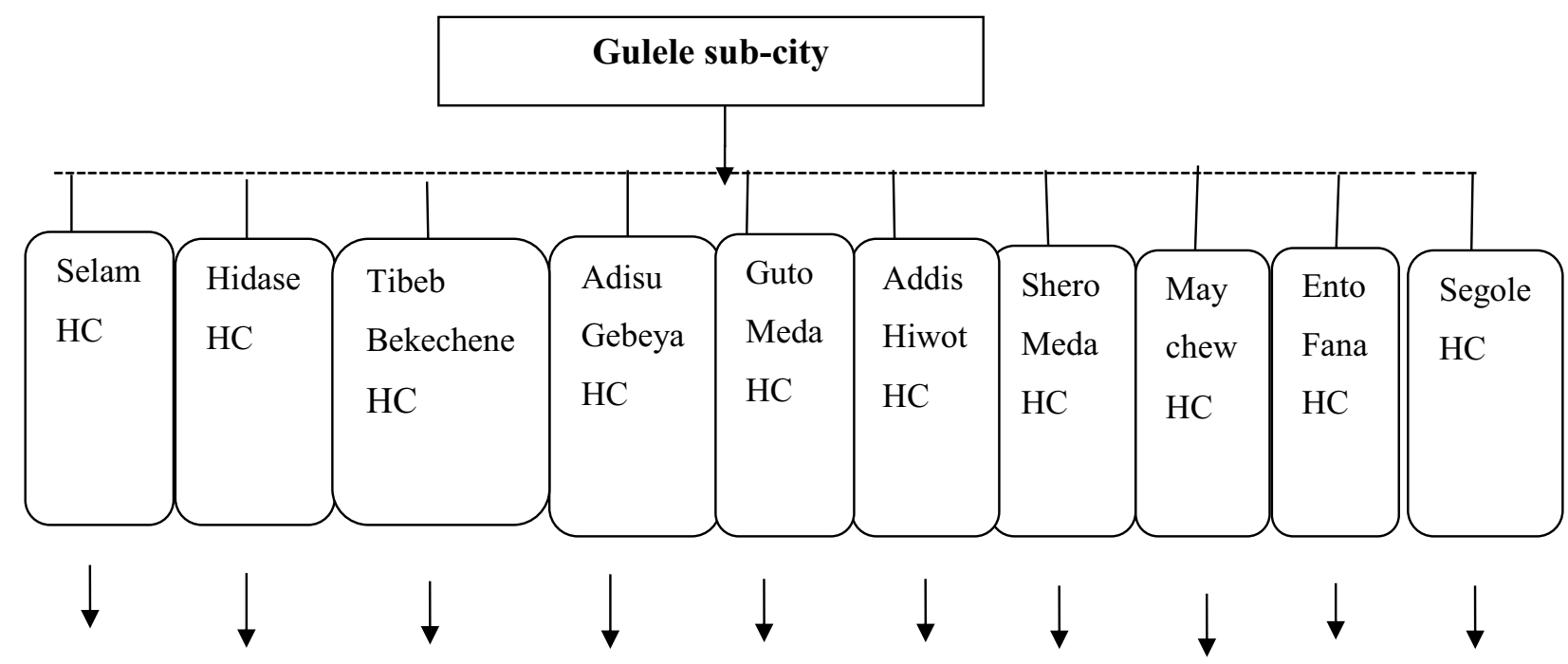

Expected client load per month

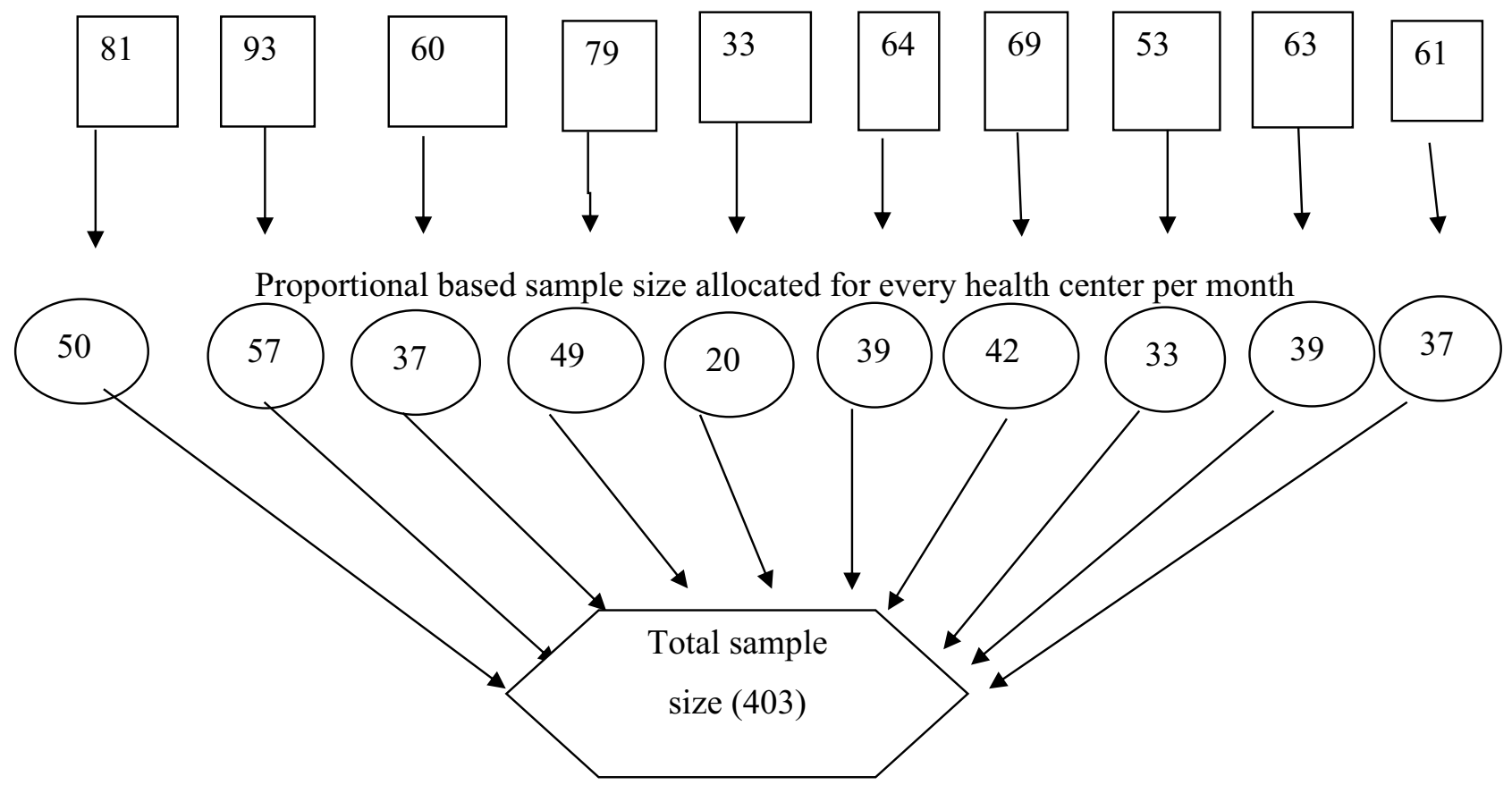

Figure I Schematic presentation of sampling procedure of adherence to iron folic for mothers attending ANC in governmental health centers in Gulele, 2019

Before the actual data collection, the questionnaire was pretested on $5 \%$ of the sample size. Data collector and supervisor was trained prior to actual data collection and the course of data collection was supervised on a daily basis. The collected data was reviewed and checked for completeness and consistency before data entry.

\section{Measurement}

\section{Adherence to IFA Supplements}

Adherence of IFA supplementation was the outcome variable in this study. According to WHO definition of Adherence of
IFA supplementation, a woman who had taken IFA supplements $\geq 90$ days or 4 days per week during the pregnancy period were considered as adherent to the supplement. ${ }^{4,24}$ So, in this study, adherence was assessed by number of days the pregnant women took the IFA supplement in the recent week. If a pregnant mother took the combined iron/folic tablet at least for 4 days in the recent week she was considered as Adherent. Otherwise she was considered as non-adherent.

\section{Knowledge About Anemia}

The knowledge of anemia was assessed by ten items assessing the causes, consequences, and prevention 
methods of anemia. The correct answer was labeled as "one" and the wrong answer was labeled as "zero." Study participants answers were categorized into two groups based on mean value and those who scored mean and above were considered to have good knowledge and those who scored below mean were considered to have poor knowledge.

\section{Knowledge of IFA Supplementation}

Knowledge of IFA supplementation among respondents was assessed by using four items assessing the benefits and negative effects of the supplements. Then, the correct answer was labeled as "one" and the wrong answer was labeled as "zero." Study participants answers were categorized into two groups based on mean value and those who scored mean and above were considered to have good knowledge and those who scored below mean were considered to have poor knowledge.

\section{Data Processing and Analysis}

Data were checked, coded, and entered into Epidata version 3.1 and exported to SPSS version 20 for analysis. Descriptive statistics such as mean and standard deviation were calculated for continuous variables and frequency and percentage was used for categorical variables. Binary and multivariable logistic regressions were used to see the relationship between adherence to IFA supplementation and its associated factors, respectively. After candidate variables were selected on bivariate logistic regression at a $p$-value $<0.25$, they were included into multivariable logistic regression to identify factors associated with adherence to IFA supplementation at a p-value $<0.05$. Odds ratio and $95 \%$ confidence interval were used to declare statistical significance of the variables.

\section{Ethical Considerations}

Ethical clearance was obtained from the Institutional Review Board (IRB) of Jimma University. A permission letter was also obtained from Addis Ababa Public Health Research and Emergency Management control. After a detailed description of the study objective, informed consent was obtained from each respondent. During the informed consent obtaining time, we encountered vulnerable participants who were pregnant and aged $\geq 15$ years. So, by following the Declaration of Helsinki, we obtained consent from themselves after detailed explanation of all procedures and confirmed that they fully understood all procedures. $^{25}$ The privacy and confidentiality of information given by each respondent was ensured and the recorded data was kept in a secured place with strict confidentiality. Health information was given for the study participants to increase their awareness and improve adherence levels after interview.

\section{Results}

\section{Sociodemographics and Economic Characteristics of Respondents}

Among the 403 study populations planned to be included in the study, 398 pregnant mothers actually participated in the study, giving a response rate of $98.76 \%$. The mean $( \pm \mathrm{SD})$ age of the respondents was $28.5( \pm 5.78)$ years. Most of the respondents $(335 ; 84.2 \%)$ were married. One fourth $(25.4 \%)$ of the mothers had no formal education, while only $21(5.3 \%)$ of the husbands had no formal education. The majority of husbands $(141 ; 37.2 \%)$ attended secondary education. More than one third of the study participants $(153 ; 38.4 \%)$ were housewives, whereas $69(17.3 \%)$ were government employed by occupation. Concerning monthly income in (ETB), 90 (22.6\%) earn $\leq 1,800$ ETB and $126(31.7 \%)$ earn $>4,500$ ETB (Table 1 ).

\section{Pregnancy and Obstetric Characteristics of Respondents}

The mean number of times mothers become pregnant was $1.8( \pm 1.14)$ and more than half of the study participants (207; 52.0\%) were prim-gravida. The mean gestational age of their current pregnancy was $26.3( \pm 8.03)$ weeks and 228 $(57.3 \%)$ of the study participants were in their third trimester. The majority $(291 ; 73.1 \%)$ attended their first ANC visit below 16 weeks. From the total mothers interviewed, only seven (1.8\%) and $70(17.6 \%)$ had a history of still birth or abortion, respectively (Table 2).

\section{Knowledge of Respondents About Anemia}

From the total study participants, 19 (4.8\%) were diagnosed with anemia and one fourth (25.4\%) developed any other health problem during their current pregnancy. The majority of the study participants $(263 ; 66.1 \%)$ knew of the illness called Anemia and around half of the women $(210 ; 52.8 \%$; and $198 ; 49.7 \%$, respectively) know the cause and consequences of anemia. Overall, 198 (49.7\%) of the respondents had good knowledge about anemia. Around 59\% (234) of the mothers perceived that pregnant women were most susceptible to develop anemia 
Table I Sociodemographic Characteristics of Pregnant Mothers Attending ANC at Health Centers in Gulele Sub City, Addis Ababa, Ethiopia, 2019

\begin{tabular}{|c|c|c|c|}
\hline Variables & Category & Frequency & (\%) \\
\hline \multirow[t]{5}{*}{ Age (years) } & $15-20$ & 18 & (4.5) \\
\hline & $20-24$ & 122 & (30.7) \\
\hline & $25-29$ & 106 & (26.6) \\
\hline & $30-34$ & 87 & $(21.9)$ \\
\hline & 35 and above & 65 & $(16.3)$ \\
\hline \multirow[t]{4}{*}{ Marital status } & Married & 335 & $(84.2)$ \\
\hline & Single & 37 & $(9.3)$ \\
\hline & Divorced & 20 & $(5.0)$ \\
\hline & Widowed & 6 & $(1.5)$ \\
\hline \multirow{4}{*}{$\begin{array}{l}\text { Maternal } \\
\text { educational status }\end{array}$} & No formal education & 101 & (25.4) \\
\hline & Primary (grade I-8) & 93 & (23.4) \\
\hline & Secondary (9-12) & 97 & (24.4) \\
\hline & College and above & 107 & (26.9) \\
\hline \multirow{5}{*}{$\begin{array}{l}\text { Husband } \\
\text { educational status }\end{array}$} & Illiterate & 18 & $(4.5)$ \\
\hline & No formal education & 21 & (5.3) \\
\hline & Primary (grade I-8) & 70 & $(17.6)$ \\
\hline & Secondary $(9-12)$ & 148 & (37.2) \\
\hline & College and above & I4I & (35.4) \\
\hline \multirow{5}{*}{$\begin{array}{l}\text { Maternal } \\
\text { Occupation }\end{array}$} & Housewife & 153 & (38.4) \\
\hline & Government & 69 & $(17.3)$ \\
\hline & $\begin{array}{l}\text { Non-Government } \\
\text { employee }\end{array}$ & 125 & (3I.4) \\
\hline & Merchant & 49 & $(12.3)$ \\
\hline & Others* & 2 & $(0.5)$ \\
\hline \multirow{5}{*}{$\begin{array}{l}\text { Monthly income } \\
\text { (ETB) }\end{array}$} & $\leq \mathrm{I}, 800$ & 90 & (22.6) \\
\hline & $\mathrm{I}, 80 \mathrm{I}-2,700$ & 65 & $(16.3)$ \\
\hline & $270 I-3,600$ & 66 & $(16.6)$ \\
\hline & $3,60 I-4,500$ & 51 & $(12.8)$ \\
\hline & $>4,500$ & 126 & (3I.7) \\
\hline
\end{tabular}

Note: Others* (daily laborer).

Abbreviation: ETB, Ethiopian Birr.

and $254(63.8 \%)$ thought that anemia is preventable. Regarding their source of information, $248(62.3 \%)$ of the respondents got information from health professionals.

\section{Respondent's Knowledge About Iron/ Folic Acid Supplement}

The majority of the study participants $(346 ; 86.9 \%)$ knew of the drug called iron/folic acid. Among these, $336(84.4 \%)$ know it prevents anemia and $224(56.3 \%)$ know it increases blood. Overall, $341(85.7 \%)$ of the respondents had good knowledge about Iron/folic acid supplement. Twenty-eight percent (114) of the respondents
Table 2 Obstetric Related Factors of Pregnant Mothers Attending ANC at Health Centers in Gulele Sub City, Addis Ababa, Ethiopia, 2019

\begin{tabular}{|l|l|c|c|}
\hline Variables & Category & Frequency & (\%) \\
\hline No of pregnancies & Prim-gravida & & $(52.0)$ \\
& Multi-gravida & 191 & $(48.0)$ \\
\hline Gestational age (GA) & First trimester & 35 & $(8.8)$ \\
& Second trimester & 135 & $(33.9)$ \\
& Third trimester & 228 & $(57.3)$ \\
\hline No of ANC visits on the & $<4$ visits & 331 & $(82.1)$ \\
current pregnancy & $\geq 4$ visits & 72 & $(17.9)$ \\
\hline History of still birth & Yes & 7 & $(1.8)$ \\
& No & 391 & $(98.2)$ \\
\hline History of abortion & Yes & 70 & $(17.6)$ \\
& No & 328 & $(82.4)$ \\
\hline GA at first ANC & $\leq 16$ weeks & 291 & $(73.1)$ \\
attendance & $>16$ weeks & 107 & $(26.9)$ \\
\hline
\end{tabular}

Abbreviation: ANC, Antenatal care.

had ever experienced any form of abnormal feeling/discomfort after taking the supplements.

\section{Health Facility Related Conditions}

Out of the 398 study participants interviewed only 63 $(15.8 \%)$ reported failure to get adequate supplements in the health facility. The majority $(295 ; 85.3 \%)$ reported that they got the supplement free of charge, and 49 (14.2\%) bought it from the pharmacy. From the total respondents, 257 (64.6\%) traveled less than 30 minutes to reach the health facility. The majority of the respondents $(342 ; 85.9 \%)$ attended health information about the iron/folic acid supplement.

\section{Adherence to Iron/Folic Acid Supplements and Reasons for}

\section{Non-Adherence}

Of the total respondents, $248(62.3 \%)$ with a 95\% $\mathrm{CI}=57.5-67.0$ of pregnant mothers were adherent to the supplement and took it at least 4 days in the recent week.

The most common reasons claimed by non-adherent mothers $(150 ; 37.7 \%)$ were fear of side-effects $(86 ; 57.3 \%)$ and unpleasant tests of the supplement $(51 ; 34.0 \%)$ (Figure 2).

\section{Factors Associated with Adherence to}

\section{Iron/Folic Acid Supplements}

Different variables including sociodemographic and economic characteristics, obstetric-related factors, knowledge 


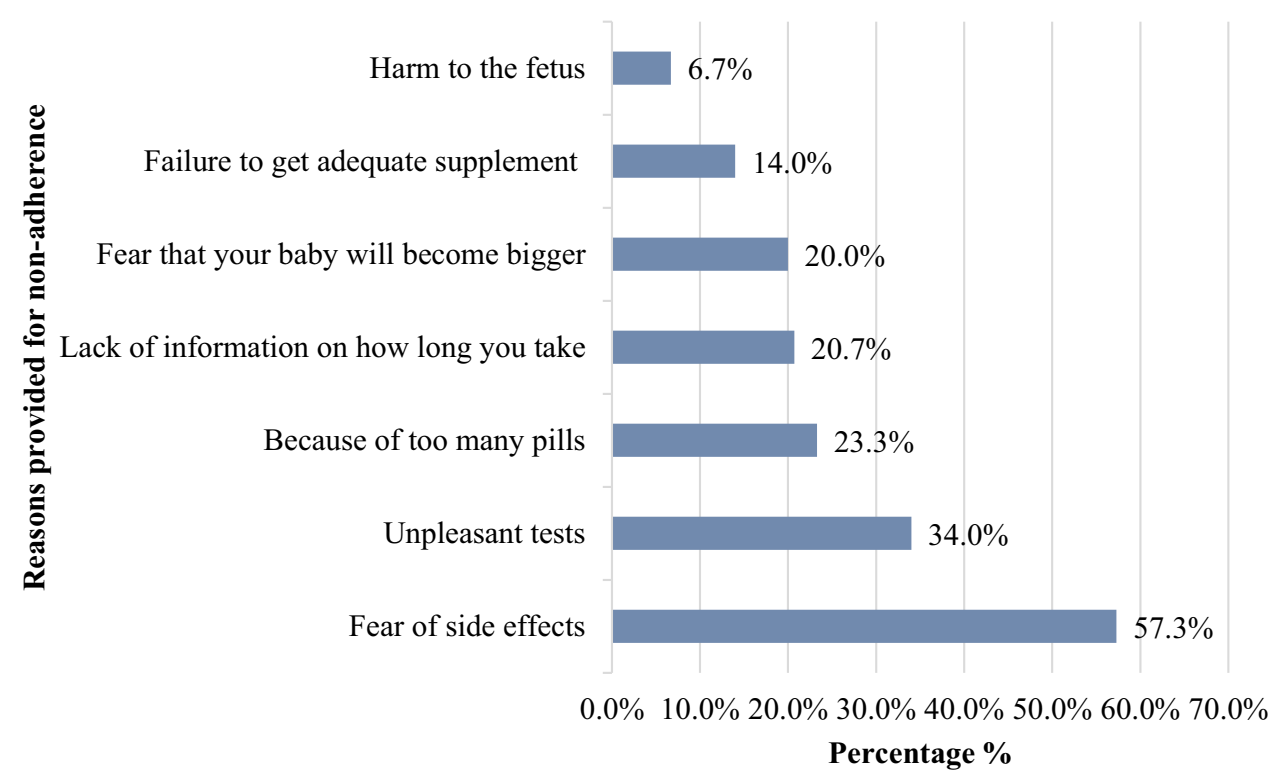

Figure 2 Reasons for not taking iron/folic acid supplement among ANC attending mothers at health centers in Gulele sub city, Addis Ababa, Ethiopia, 20I9 ( $\mathrm{n}=150$ ).

about anemia, knowledge about iron/folic acid supplements, and Health facility-related factors were tested for their association with adherence behavior of the mother on bivariate logistic regression at a p-value $<0.25$.

On bivariate analysis, maternal educational status, number of pregnancies, number of ANC visits, knowledge about IFA supplement, knowledge about anemia, diagnosed to have anemia in current pregnancy, developed any other health problem during current pregnancy, attended health information about iron/folic acid supplement and forgetfulness were identified as candidate variables for multivariable analysis.

Finally, on multivariable logistic regression, maternal educational status, knowledge about anemia, developing any other health problem during current pregnancy, attending health information about iron/folic acid supplement, and forgetfulness remained statistically significant factors associated with IFA supplement adherence at $p$-value $<0.05$.

Mothers who had no formal education were 2-times more likely $(\mathrm{AOR}=2.37 ; 95 \% \mathrm{CI}=1.25-4.51)$ to be nonadherent to iron/folic acid supplements compared with participants who had college and above educational status.

Mothers who had poor knowledge about anemia were 2-times more likely ( $\mathrm{AOR}=1.97 ; 95 \% \mathrm{CI}=1.24-3.13)$ to be non-adherent to iron/folic acid supplements compared with those who had good knowledge about anemia. Pregnant women who developed any other health problem during the current pregnancy had a significant association with non-adherence to iron/folic acid supplements $(\mathrm{AOR}=2.59$; 95\% CI $=1.55-4.32)$ compared with their counterparts. Mothers who attended health information about iron/folic acid supplement (AOR=2.06; 95\% $\mathrm{CI}=1.08-3.92)$ and those who forget to take the supplement $(\mathrm{AOR}=2.23$; $95 \% \mathrm{CI}=1.40-3.56)$ were more likely to be non-adherent compared with their counterparts (Table 3).

\section{Discussion}

This study was aimed to assess adherence to iron/folic acid supplement and associated factors among ANC attending mothers in Gulele sub city governmental health centers and found that $62.3 \%$ of pregnant mothers were adherent to the supplement and maternal educational status, knowledge about anemia, developing any other health problem during the current pregnancy, attending health information about iron/folic acid supplement, and forgetfulness were factors associated with non-adherence to iron/folic acid supplements.

The proportion of mothers adhered to combined iron/ folic acid supplement tablets in this study were $62.3 \%$ (95\% CI=57.50-67.00). This finding is comparable with the finding of studies conducted in south India (64.7\%), Asella town (59.8\%), and Akaki Kality; Addis Abeba $(60.9 \%){ }^{15,23,26}$ However, it is higher when compared with studies conducted in Uganda, North Western Zone of Tigray, Ethiopia, and South East Ethiopia in which the proportion of participants adhered to the supplement were $12 \%, 37.2 \%$, and $18 \%$, respectively. ${ }^{16,17,27}$ These great 
Table 3 Factors Associated with Non-Adherence to Iron/Folic Acid Supplements Among ANC Attending Mothers at Health Centers in Gulele Sub City, Addis Ababa, Ethiopia, 2019

\begin{tabular}{|c|c|c|c|c|c|}
\hline & \multicolumn{2}{|c|}{ Adherence to IFs } & \multirow[t]{3}{*}{ COR $(95 \% \mathrm{Cl})$} & \multirow[t]{3}{*}{ AOR $(95 \% \mathrm{Cl})$} & \multirow[t]{3}{*}{ p-value } \\
\hline & No & Yes & & & \\
\hline & $\mathbf{N}(\%)$ & $\mathbf{N}(\%)$ & & & \\
\hline \multicolumn{6}{|l|}{ Maternal educational status } \\
\hline No formal education & $50(49.5)$ & $51(50.5)$ & $2.77(1.55-4.95)$ & $2.37(\mathrm{I} .25-4.5 \mathrm{I})$ & $0.009 *$ \\
\hline Primary (grade I-8) & $38(40.9)$ & $55(59.1)$ & $1.82(1.03-3.22)$ & $1.62(0.86-3.03)$ & 0.133 \\
\hline Secondary $(9-12)$ & $34(35.1)$ & $63(64.9)$ & $\mathrm{I} .42(0.80-2.5 \mathrm{I})$ & $1.36(0.73-2.53)$ & 0.332 \\
\hline College and above & $28(26.2)$ & $79(73.8)$ & 1 & 1 & \\
\hline \multicolumn{6}{|l|}{ No of pregnancies } \\
\hline Prim-gravida & $89(43.0)$ & II $8(57.0)$ & $1.61(1.07-2.42)$ & $1.47(0.93-2.33)$ & 0.098 \\
\hline Multi-gravida & $61(31.9)$ & $130(68.1)$ & 1 & 1 & \\
\hline \multicolumn{6}{|c|}{ No of ANC visits on the current pregnancy } \\
\hline$<4$ visits & $132(40.4)$ & $195(59.6)$ & $1.99(1.12-3.56)$ & $1.80(0.95-3.40)$ & 0.071 \\
\hline$\geq 4$ visits & $18(25.4)$ & $53(74.6)$ & 1 & I & \\
\hline \multicolumn{6}{|c|}{ Knowledge about IFA supplements } \\
\hline Poor Knowledge & $28(49.1)$ & $29(50.9)$ & $1.73(0.99-3.05)$ & $1.66(0.86-3.19)$ & 0.128 \\
\hline Good Knowledge & $122(35.8)$ & $219(64.2)$ & 1 & 1 & \\
\hline \multicolumn{6}{|l|}{ Knowledge about anemia } \\
\hline Poor Knowledge & $86(43.4)$ & $\mathrm{II} 2(56.6)$ & $1.63(1.08-2.46)$ & $1.97(1.24-3.13)$ & $0.004 *$ \\
\hline Good knowledge & $64(32.0)$ & $136(68.0)$ & 1 & 1 & \\
\hline \multicolumn{6}{|c|}{ Diagnosed to have anemia during current pregnancy } \\
\hline No & $148(39.2)$ & $230(60.8)$ & $5.79(1.32-25.32)$ & $4.15(0.90-19.06)$ & 0.067 \\
\hline Yes & $2(10.0)$ & $18(90.0)$ & 1 & 1 & \\
\hline \multicolumn{6}{|c|}{ Developed any other health problem during current pregnancy } \\
\hline Yes & $57(56.4)$ & $44(43.6)$ & $2.84(1.79-4.52)$ & $2.59(1.55-4.32)$ & $<0.00 I^{*}$ \\
\hline No & $93(31.3)$ & $204(68.7)$ & 1 & 1 & \\
\hline \multicolumn{6}{|c|}{ Attended health information about iron/folic acid supplement } \\
\hline No & $33(55.9)$ & $26(44.1)$ & $2.41(1.38-4.22)$ & $2.06(1.08-3.92)$ & $0.029 *$ \\
\hline Yes & $117(34.5)$ & $222(65.5)$ & 1 & 1 & \\
\hline \multicolumn{6}{|l|}{ Forgetfulness } \\
\hline Yes & $74(52.5)$ & $67(47.5)$ & $2.63(1.72-4.03)$ & $2.23(1.40-3.56)$ & $0.001 *$ \\
\hline No & $76(29.6)$ & |8| (70.4) & 1 & I & \\
\hline
\end{tabular}

Notes: NB; *P-value $<0.05$ was statistically significant on multivariable. Abbreviation: IFA, Iron folic acid.

discrepancies were due to differences in population considered for the study and the time period used for assessing adherence behavior.

This study found that mothers who had no formal education were more likely non-adherent to iron/folic acid supplements compared to those who attended college and above educational status. This finding is in line with a study conducted in Asella town, Ethiopia and southeast Ethiopia $^{15,17}$ which found that better educated mothers were more adherent compared to those who cannot read and write. This might be due to the effect of educational status on health literacy level which affects the ability to 
differentiate the benefit and risks of adhering to the supplement. In addition those mothers who educated more can have exposure to different sources of information promoting benefits of adhering to the supplements.

The study participants who had poor knowledge about anemia were more likely non-adherent to combined iron/ folic acid supplements compared with those who had good knowledge about anemia. This finding is consistent with a study conducted in Hossana town, Ethiopia, and eight rural districts of Ethiopia which found that those who had no comprehensive knowledge about anemia less likely utilize the Iron supplement. ${ }^{12,18}$ This could be due to the reason that those mothers who know the causes, consequences, and prevention mechanism of anemia were more adherent because of fear of the effects of iron deficiency anemia on both mothers and fetus.

Developing of any other health problems during current pregnancy also has a positive relationship with nonadherence behavior of mothers. This study finding is in line with a study conducted in Northern Tanzania which found that those mothers with any comorbidity during pregnancy were less adherent to combined iron/folate supplement compared with their counterparts. ${ }^{9}$ This might be due to the reason that if mother develop any health problem, she might be treated for that health problem with other pills and the pill burden she encounters at that time may lead her to miss or stop the iron/folic acid supplement prescribed for her.

This study result indicates that those mothers who attended health information about iron/folic acid supplement were more likely non-adherent to combined iron/ folate supplement than their counterparts. This finding is supported by a systematic review conducted in Ethiopia ${ }^{22}$ and a study done in Harare; Zimbabwe. ${ }^{28}$ The possible explanation could be during the educational session mothers become knowledgeable and assured of the benefits of taking the supplement by health professionals, leading to enhance the adherence behavior of mothers.

Forgetting to take the iron supplement was the other positively associated variable with adherence behavior. Similarly, forgetfulness was the commonest reason forwarded by the mother not to comply with the supplements. ${ }^{14,26,29}$ This finding suggests the importance of family support during pregnancy to remind taking of their pills on time and evidence showed that mothers who got high support from their husbands were more likely to consume more IFA supplements. ${ }^{30}$

The possible limitation of this study includes the selfreporting mechanism used to assess adherence behavior of the mother, it may overestimate the proportion of adherent mothers due to social desirability bias. In addition, recall bias is also the other expected bias in this study.

\section{Conclusion}

Compared with other studies, the adherence status of the mother was considered as medium. Educational status, knowledge about anemia, exposure to information, experiencing of health problem, and forgetfulness were factors associated with adherence to the supplement. This finding shades light on the importance of improving dissemination of information about the supplements and designing a reminder mechanism to improve adherence behavior.

\section{Acknowledgment}

We would like to acknowledge Gulele health bureau and healthcare professionals working at all health centers for their cooperation in every possible way.

\section{Disclosure}

The authors reported no conflicts of interest for this work.

\section{References}

1. World Health organization. Worldwide prevalence of anaemia 19932005: WHO global database on anaemia; 2008:2008.

2. Mclean E, Cogswell M, Egli I, Wojdyla D, De BB. Worldwide prevalence of anaemia, WHO Vitamin and Mineral Nutrition Information System, 1993-2005. Public Health Nutr. 2008;12(4):444-454. doi:10.1017/S1368980008002401

3. Rahman MM, Abe SK, Rahman MS, et al. Maternal anemia and risk of adverse birth and health outcomes in low- and middle-income countries: systematic review and meta-analysis. Am J Clin Nutr. 2016;103(2):495-504. doi:10.3945/ajcn.115.107896

4. WHO. Guideline: daily iron and folic acid supplementation in pregnant women. Geneva; 2012

5. Maggini S, Pierre A, Calder PC. Immune function and micronutrient requirements change over the life course. Nutrients. 2018;10. doi:10.3390/nu10101531

6. Titaley CR, Dibley MJ, Roberts CLAK. Combined iron/folic acid supplements and malaria prophylaxis reduce neonatal mortality in 19 sub-Saharan African countries. Am J Clin Nutr. 2010;92(1):235-243. doi:10.3945/ajen.2009.29093

7. Nisar YBDM, Dibley MJ. Earlier initiation and use of a greater number of iron-folic acid supplements during pregnancy prevents early neonatal deaths in Nepal and Pakistan. PLoS One. 2014;9(11): e112446. doi:10.1371/journal.pone.0112446

8. Maina-Gathigi L, Omolo J, Wanzala P, et al. Utilization of folic acid and iron supplementation services by pregnant women attending an antenatal clinic at a regional referral hospital in Kenya. Matern Child Heal J. 2013;17:1236-1242. doi:10.1007/s10995-012-1120-x

9. Ogundipe O, Hoyo C, Oneko O, Manongi R, Lie RT, Daltveit AK. Factors associated with prenatal folic acid and iron supplementation among 21, 889 pregnant women in Northern Tanzania: a cross-sectional hospital-based study. BMC Public Health. 2012;12:481. doi:10.1186/1471-2458-12-481 
10. Warvadekar K, Reddy JC, Sharma S, Dearden KA, Raut MK. Sociodemographic and economic determinants of adherence to iron intake among pregnant women in selected low and lower middle income countries in Asia: insights from a cross-country analyses of global demographic and health surveys. Int J Commun Med Public Heal. 2018;5(4):1552-1569. doi:10.18203/2394-6040.ijcmph20181234

11. Central Statistical Agency (CSA) [Ethiopia] and ICF. 2016 ethiopia demographic and health survey key findings. Addis Ababa, Ethiopia, and Rockville, Maryland, USA: CSA and ICF; 2017.

12. Gebremedhin S, Samuel A, Mamo G, Moges T, Assefa T. Coverage, compliance and factors associated with utilization of iron supplementation during pregnancy in eight rural districts of Ethiopia: a cross-sectional study. BMC Public Health. 2014;14:1-8. doi:10.1186/1471-2458-14-607

13. Ibrahim ZM, El-hamid SABD, Mikhail H, Khattab MS. Assessment of adherence to iron and folic acid supplementation and prevalence of anemia in pregnant women. MedJCairo Univ. 2011;79(2):115-121.

14. Galloway RMJ. Determinants of compliance with iron supplementation: supplies, side effects, or psychology? Soc Sci Med. 1994;39 (3):381-390. doi:10.1016/0277-9536(94)90135-X

15. Niguse WMR. Determinants of adherence to iron folic acid supplementation among determinants of adherence to iron folic acid supplementation among pregnant women attending antenatal clinic in asella town, Ethiopia. Int J Ther Appl. 2018;35:60-67.

16. Gebre A, Mulugeta AEB. Assessment of factors associated with adherence to iron-folic acid supplementation among urban and rural pregnant women in North Western Zone of Tigray, Ethiopia: comparative Study. Int J Nutr Food Sci. 2015;4:2.

17. Haile MT, Jeba ABHM. Compliance to prenatal iron and folic acid supplement and associated factors among women during pregnancy in south east Ethiopia: a cross-sectional study. J Nutr Heal Food Eng. 2017;7(2):272-277.

18. Jikamo BSM. Non-adherence to iron/folate supplementation and associated factors among pregnant women who attending antenatal care visit in selected public Health Institutions at Hosanna Town, Southern Ethiopia. J Nutr Disord Ther. 2018;8:2. doi:10.4172/21610509.1000230

19. Molla T, Guadu T, Muhammad EA, Hunegnaw MT. Factors associated with adherence to iron folate supplementation among pregnant women in West Dembia district, northwest Ethiopia: a cross sectional study. BMC Res Notes. 2019;12(1):1-6. doi:10.1186/s13104-0194045-2

20. Birhanu TM, Birarra MK, Mekonnen FA. Compliance to iron and folic acid supplementation in pregnancy, Northwest. BMC Res Notes. 2018;11(345):3-7. doi:10.1186/s13104-018-3433-3
21. Getachew M, Abay M, Zelalem H, Gebremedhin T, Grum T. Magnitude and factors associated with adherence to Iron-folic acid supplementation among pregnant women in Eritrean refugee camps, northern Ethiopia. BMC Pregnancy Childbirth. 2018;18(83):1-8. doi:10.1186/s12884-018-1716-2

22. Desta M, Kassie B, Chanie H, Mulugeta H, Yirga T, Temesgen H. Adherence of iron and folic acid supplementation and determinants among pregnant women in Ethiopia: a systematic review and meta-analysis. Reprod Health. 2019;16(182):1-14. doi:10.1186/ s12978-019-0848-9

23. Gebreamlak B, Dadi AF, Atnafu A. High adherence to iron/folic acid supplementation during pregnancy time among antenatal and postnatal care attendant mothers in governmental health centers in akaki kality Sub City, Addis Ababa, Ethiopia: hierarchical negative binomial poisson regres. PLoS One. 2017;12(1):1-11. doi:10.1371/journal.pone. 0169415

24. Health FM of. Guidelines for prevention and control of micronutrient deficiencies in Ethiopia; 2016.

25. Manti S, Licari A. How to obtain informed consent for research. Breathe. 2018;14(2):145-152. doi:10.1183/20734735.001918

26. Mithra P, Unnikrishnan B, Rekha T, Nithin K, Mohan K. Compliance with iron-folic acid (IFA) therapy among pregnant women in an urban area of south India. African Heal Sci. 2014;14(1):255-260. doi:10.4314/ahs.v14i1.39

27. Kiwanuka TS, Ononge S, Kiondo P, Namusoke F. Adherence to iron supplements among women receiving antenatal care at mulago national referral hospital, Uganda cross sectional study. BMC Res Notes. 2017;10(510):1-6. doi:10.1186/s13104-017-2834-z

28. Tinago $\mathrm{CB}$, Ingram LA, Blake CE, Frongillo EA. Individual and structural environmental in fl uences on utilization of iron and folic acid supplementation among pregnant women in Harare, Zimbabwe. Matenal Child Nutr. 2017;13:1-11.

29. Galloway R, Dusch E, Elder L, et al. Women's perceptions of iron deficiency and anemia prevention and control in eight developing countries. Soc Sci Med. 2002;55(4):529-544. doi:10.1016/S02779536(01)00185-X

30. Nguyen PH, Sanghvi T, Kim SS, et al. Factors influencing maternal nutrition practices in a large scale maternal, newborn and child health program in Bangladesh. PLoS One. 2017;12(7):1-17. doi:10.1371/ journal.pone. 0179873
Patient Preference and Adherence

\section{Publish your work in this journal}

Patient Preference and Adherence is an international, peer-reviewed, open access journal that focusing on the growing importance of patient preference and adherence throughout the therapeutic continuum. Patient satisfaction, acceptability, quality of life, compliance, persistence and their role in developing new therapeutic modalities and compounds to optimize clinical outcomes for existing disease states are major areas of interest for the journal. This journal has been accepted for indexing on PubMed Central. The manuscript management system is completely online and includes a very quick and fair peer-review system, which is all easy to use. Visit http:/ www.dovepress.com/testimonials.php to read real quotes from published authors. 